\title{
Rizatriptan for the acute treatment of migraine: Consistency, preference, satisfaction, and quality of life
}

\author{
This article was published in the following Dove Press journal: \\ Patient Preference and Adherence \\ II August 2009 \\ Number of times this article has been viewed
}

\author{
Farnaz Amoozegar \\ Tamara Pringsheim \\ Calgary Headache Assessment \\ and Management Program, \\ Department of Clinical \\ Neurosciences, University \\ of Calgary, Calgary, AB, Canada
}

Correspondence: Tamara Pringsheim C4-43I, Alberta Children's Hospital, 2888 Shaganappi Trail NW, Calgary AB, T3B 6A8, Canada

$\mathrm{Tel}+\mid 403955792$ I

Fax +I 4039555990

Email tmprings@ucalgary.ca

\begin{abstract}
Rizatriptan is a $5 \mathrm{HT}$ (IB/ID) agonist with proven efficacy in the acute treatment of migraine headache. We performed a systematic review of the literature for clinical trials of rizatriptan incorporating important patient outcomes including consistency of response, preference, satisfaction, and quality of life. We found evidence that rizatriptan provides consistent relief of migraine attacks and that patients prefer rizatriptan over other treatments because of its speed of relief. Patient satisfaction with rizatriptan is significantly higher than placebo, but appears equivalent to most other triptans. Migraine-specific quality of life at 24 hours is significantly better in patients treated with rizatriptan compared to placebo, while overall long-term quality of life is less affected. The published clinical trials included in this systematic review are subject to bias due to the open-label nature of preference trials and the doses chosen for comparison in head-to-head trials.
\end{abstract}

Keywords: migraine, rizatriptan, patient preference

\section{Background}

Rizatriptan is a $5 \mathrm{HT}(1 \mathrm{~B} / 1 \mathrm{D})$ receptor agonist and one of seven triptans available for acute migraine headache treatment. Rizatriptan's efficacy and tolerability have been demonstrated by multiple randomized placebo controlled studies. A systematic review and meta-analysis of the available triptans in 2001 looked at 53 double-blind, randomized, placebo-controlled trials and compared the various triptans. ${ }^{1}$ The authors found that all oral triptans were effective and well tolerated. Based on their metaanalysis, $10 \mathrm{mg}$ rizatriptan, $80 \mathrm{mg}$ eletriptan, and $12.5 \mathrm{mg}$ almotriptan provide the highest likelihood of consistent success.

In contrast to the traditional measures of efficacy and tolerability, a much smaller number of studies have looked at patient satisfaction or preference for rizatriptan and quality of life measures. In this systematic review, our goal is to review the literature on patient satisfaction and preference, consistency of response, as well as studies analyzing quality of life for rizatriptan.

Preference and satisfaction for a certain medication is based on multiple factors. These include speed and degree of pain relief, headache recurrence, adverse symptoms, ease of medication administration, functional disability, and consistency of effect. Therefore, the composite endpoint of patient preference unifies these factors into a single global measure incorporating efficacy and tolerability, and is meaningful to both patients and physicians. In addition, studies have shown that patient preference is a sensitive clinical trial endpoint. ${ }^{2}$ 
Quality of life is also a very important measure for patients taking acute migraine medications. Many patients can become severely disabled with their migraines, rendering them unable to go to work, school, or even to do daily household duties. Standardized and validated quality of life measures are available for migraine and are crucial to consider in addition to traditional measures of efficacy and tolerability.

\section{Methods}

A systematic review of clinical trials of rizatriptan for the treatment of migraine headache was performed. For the identification of studies considered for this review, a search strategy was developed for Ovid MEDLINE (1950 to April 2009) and EMBASE (1980 to April 2009). A very broad search strategy was employed in order to maximize the chance of finding relevant trials. The MEsH heading "migraine disorders" was cross-referenced with the term "rizatriptan" as a keyword. We limited our search to articles written in English. Clinical trials were included in the review if they had outcome measures pertaining to patient preference, patient satisfaction, consistency of response, or quality of life. Data on patient satisfaction was only assessed from double-blind randomized studies. We included both open and double-blind trials using patient preference, consistency of response and quality of life as outcomes. Titles and abstracts identified by the literature search were screened for eligibility by two independent reviewers (TP and FA). Papers that could not be excluded with certainty on the basis of the information contained in the title or abstract were retrieved in full for screening by both authors. Data on patient satisfaction, preference, consistency, and quality of life were abstracted by one researcher.

The combined search strategies yielded 1,461 abstracts. After analysis of the abstracts, 64 full text articles were reviewed. Twenty-four trials met our inclusion criteria and were included in the review (see Figure 1 for study flow diagram).

Meta-analysis was performed by treatment comparison type (ie, placebo, other triptans) if more than one trial was performed. Odds ratios (OR) were calculated with $95 \%$ confidence intervals (CI). OR from multiple studies were tested for homogeneity using the chi-squared test and by calculating the I-squared statistic. If study estimates were homogenous, they were combined using a fixed-effects model. When studies with heterogeneous results were clinically similar, the study estimates were combined using a randomeffects model. Clinical heterogeneity was assessed by looking at trial and patient characteristics and outcome measures. Trials required similar inclusion and exclusion criteria, clinical populations, and common outcome measures in order to be combined statistically using meta-analysis. Clinically heterogeneous studies were not statistically combined. We used Review Manager 5 software (available from the Cochrane Collaboration) to perform meta-analysis.

\section{Results Consistency}

Three studies have looked specifically at consistency of response for patients using rizatriptan for their acute migraine headaches. These studies were not combined using metaanalysis due to clinical heterogeneity; the trials employed differing research protocols and outcome measures (see Table 1 for summary of data). Dahlof and colleagues ${ }^{3}$ performed post-hoc analysis on data from a randomized double-blind, placebo-controlled trial, to determine "within-patient consistency" of response to rizatriptan. Within-patient consistency describes the percentage of patients who have a response to medication in a certain proportion of their migraine attacks. Patients treated four attacks, with four groups receiving rizatriptan $10 \mathrm{mg}$ for three of four attacks, and placebo for the other attack, in different sequences, and the final group receiving rizatriptan $10 \mathrm{mg}$ for all four attacks. The primary outcome of this study was pain relief at two hours. In patients who treated three of four attacks with rizatriptan, $86 \%$ had pain relief in at least two of those three attacks. In those treating all four attacks with rizatriptan, $73 \%$ had pain relief in at least three of four attacks.

Block and colleagues ${ }^{4}$ looked at the consistency of effect with rizatriptan compared to the standard treatment for migraine. This multicenter study randomized 1,831 patients with more than 46,000 attacks to rizatriptan $5 \mathrm{mg}, 10 \mathrm{mg}$, or standard care. The rizatriptan groups were single-blinded and the standard care group was unblinded. The majority of patients in the standard care group used sumatriptan, alone or with nonsteroidal anti-inflammatory drugs (NSAIDs) or acetaminophen. The primary outcome was pain relief at two hours. For the $10 \mathrm{mg}$ dose of rizatriptan, a median of $90 \%$ of attacks were relieved, as compared to $80 \%$ for rizatriptan $5 \mathrm{mg}$, and $70 \%$ for standard care $(\mathrm{p}<0.05)$. The percentage of attacks relieved was similar for patients who treated just a few attacks as compared to those treating dozens of attacks.

Göbel and colleagues ${ }^{5}$ looked at the efficacy and tolerability of rizatriptan $10 \mathrm{mg}$ treating up to three attacks of migraine in an open-label study. They found no evidence 


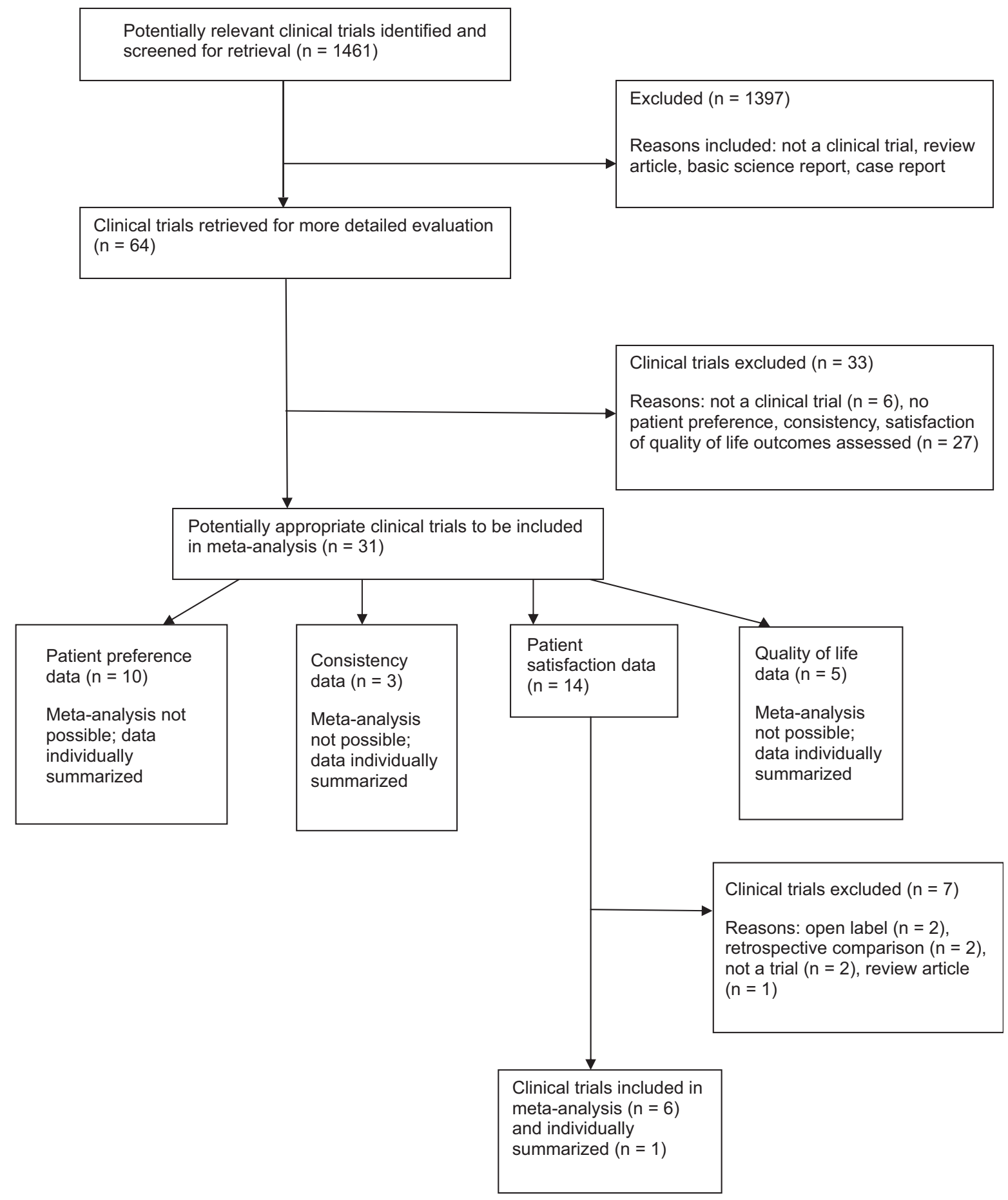

Figure I Flow diagram of the selection of clinical trials and studies.

of tolerance to repeated use and headache relief was noted in $79 \%$ of attacks.

\section{Preference}

Ten open-label studies have looked at patient preference for rizatriptan versus other triptans and nontriptan medications (see Table 2 for summary of study data). These studies generally involve a cross-over design, in which the patient is instructed to treat two moderate to severe migraine attacks; one with rizatriptan and the other with another medication. At the final visit, patients are asked to complete a validated "Preference Questionnaire". In these, the patient is asked which of the two medications they prefer, or if they have no preference. In those expressing a preference, they are then 
Table I Summary of studies looking at consistency of effect for rizatriptan

\begin{tabular}{|c|c|c|c|c|}
\hline Study & Sample size & Comparison & Outcome measures & Results \\
\hline Dahlof, $2000^{3}$ & 250 & $\begin{array}{l}\text { Rizatriptan } 10 \mathrm{mg} \text { in three of four } \\
\text { attacks, or rizatriptan } 10 \mathrm{mg} \text { in all } \\
\text { four attacks }\end{array}$ & Pain relief at two hours & $\begin{array}{l}\text { Three of four attacks: } 86 \% \text { pain relief } \\
\text { at two hours in at least two of three } \\
\text { attacks. All four attacks: } 73 \% \text { pain relief } \\
\text { in at least three of four attacks }\end{array}$ \\
\hline Block, $1998^{4}$ & $|, 83|$ & $\begin{array}{l}\text { Rizatriptan } 10 \mathrm{mg}, 5 \mathrm{mg} \text { or standard } \\
\text { treatment }\end{array}$ & Pain relief at two hours & $\begin{array}{l}90 \% \text { for } 10 \mathrm{mg}, 80 \% \text { for } 5 \mathrm{mg}, 70 \% \text { for } \\
\text { standard treatment }\end{array}$ \\
\hline Göbel, 200I ${ }^{5}$ & 25,501 & $\begin{array}{l}\text { Tolerance to rizatriptan use in up to } \\
\text { three attacks }\end{array}$ & Tolerance, headache relief & $\begin{array}{l}\text { No tolerance with repeated use } 79 \% \\
\text { had headache relief within one hour }\end{array}$ \\
\hline
\end{tabular}

asked to choose the most important reason. Reasons include relieving headache faster, returning to normal activities more quickly, fewer side effects, ease of taking the medication, headache recurrence with other treatment, and faster relief of nausea, photophobia, and/or phonophobia. Meta-analysis of these studies was not possible due to clinical heterogeneity.

Láinez and colleagues ${ }^{6}$ compared the rizatriptan $10 \mathrm{mg}$ wafer to eletriptan $40 \mathrm{mg}$ tablets. Of 372 patients, 342 patients (92\%) expressed a preference. Of these, 61\% preferred the rizatriptan $10 \mathrm{mg}$ wafer over eletriptan $(\mathrm{p}<0.001)$. The most common reason given for the preference was speed of headache relief.

Loder and colleagues ${ }^{7}$ compared rizatriptan $10 \mathrm{mg}$ with sumatriptan $50 \mathrm{mg}$ tablets. Of 472 patients, 374 expressed a preference. Of these, 213 (57\%) preferred rizatriptan and the remainder $(43 \%)$ preferred sumatriptan $(\mathrm{p}=0.009)$.
The most important reason for preference was faster pain relief. Pascual ${ }^{8}$ also did a similar study with these two medications. Of 425 patients, 44 patients (10.4\%) did not express a preference. Of the 381 patients who did express a preference, 245 (64.3\%) preferred rizatriptan and 136 patients $(35.7 \%)$ preferred sumatriptan $(\mathrm{p} \leq 0.001)$. Faster relief of headache was again the most important reason.

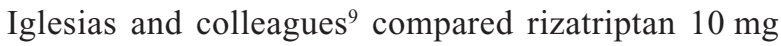
with almotriptan $12.5 \mathrm{mg}$. Of 267 patients, 209 recorded a preference, with 114 (54.5\%) preferring almotriptan, and $95(45.5 \%)$ preferring rizatriptan $(\mathrm{p}=0.1663)$. The results in this case were not statistically significant. Faster headache relief was again the most important reason for preference.

An open-label study by $\mathrm{Ng}$-Mak and colleagues ${ }^{10}$ compared rizatriptan with patients' usual care oral triptans. These included sumatriptan (49.6\%), zolmitriptan (15.2\%),

Table 2 Summary of studies looking at preference for rizatriptan versus other medications

\begin{tabular}{|c|c|c|c|c|}
\hline Study & Sample size & Comparison & Outcome & Results \\
\hline Láinez, $2006^{6}$ & 372 & $\begin{array}{l}\text { Rizatriptan } 10 \mathrm{mg} \text { or eletriptan } \\
40 \mathrm{mg}\end{array}$ & Preference for one treatment & $61 \%$ preferred rizatriptan \\
\hline Loder, $2001^{7}$ & 472 & $\begin{array}{l}\text { Rizatriptan } 10 \mathrm{mg} \text { or } \\
\text { sumatriptan } 50 \mathrm{mg}\end{array}$ & Preference for one treatment & $57 \%$ preferred rizatriptan \\
\hline Pascual, 200 ${ }^{8}$ & 425 & $\begin{array}{l}\text { Rizatriptan } 10 \mathrm{mg} \text { or } \\
\text { sumatriptan } 50 \mathrm{mg}\end{array}$ & Preference for one treatment & $\begin{array}{l}10 \% \text { had no preference } 64 \% \text { preferred } \\
\text { rizatriptan }\end{array}$ \\
\hline Díez, $2007^{9}$ & 267 & $\begin{array}{l}\text { Rizatriptan } 10 \mathrm{mg} \text { or } \\
\text { almotriptan } 12.5 \mathrm{mg}\end{array}$ & Preference for one treatment & $54.5 \%$ preferred almotriptan \\
\hline Ng-Mak, $2007^{10}$ & 673 & $\begin{array}{l}\text { Rizatriptan } 10 \mathrm{mg} \text { or usual care } \\
\text { triptans }\end{array}$ & Preference for one treatment & $\begin{array}{l}19.6 \% \text { no preference, } 46.6 \% \text { preferred } \\
\text { rizatriptan, } 33.7 \% \text { preferred another } \\
\text { triptan }\end{array}$ \\
\hline Adelman, 2000"' & 367 & Rizatriptan tablet vs wafer & Preference for one treatment & No preference found \\
\hline Christie, $2003^{12}$ & 439 & $\begin{array}{l}\text { Rizatriptan } 10 \mathrm{mg} \text { or ergotamine } \\
\mathrm{I} \mathrm{mg} / \text { caffeine } 100 \mathrm{mg}\end{array}$ & Preference for one treatment & $\begin{array}{l}89 \% \text { expressed preference. Of these, } \\
69.9 \% \text { preferred rizatriptan }\end{array}$ \\
\hline Pascual, $2005^{13}$ & $\mathrm{I}, 353$ & $\begin{array}{l}\text { Rizatriptan } 10 \text { mg or usual } \\
\text { nontriptan therapy }\end{array}$ & Preference for one treatment & $78.8 \%$ preferred rizatriptan \\
\hline Bell, $2006^{14}$ & 1,489 & $\begin{array}{l}\text { Rizatriptan } 10 \mathrm{mg} \text { or usual care } \\
\text { meds }\end{array}$ & Preference for one treatment & $\begin{array}{l}19.6 \% \text { had no preference. } 58 \% \text { preferred } \\
\text { rizatriptan }\end{array}$ \\
\hline Láinez, $2005^{15}$ & 259 & Rizatriptan $10 \mathrm{mg}$ or usual meds & Preference for one treatment & $89 \%$ preferred rizatriptan \\
\hline
\end{tabular}


eletriptan (13.8\%), almotriptan (11.7\%), frovatriptan (5.1\%) and naratriptan (4.6\%). Regarding medication preference, $46.6 \%$ preferred rizatriptan, $33.7 \%$ preferred another oral triptan, and $19.6 \%$ expressed no preference.

The rizatriptan tablet and wafer have also been compared. ${ }^{11}$ Of 367 patients, no preference was found for the tablet versus the wafer.

Rizatriptan $10 \mathrm{mg}$ tablet was compared with two ergotamine $1 \mathrm{mg} /$ caffeine $100 \mathrm{mg}$ tablets in a study of 439 patients. ${ }^{12}$. $89.1 \%$ of patients expressed a preference. Of these, $69.9 \%$ preferred rizatriptan $(\mathrm{p} \leq 0.001)$. Faster relief of headache was the most important reason.

Another similar study ${ }^{13}$ looked at rizatriptan $10 \mathrm{mg}$ wafer versus patients' usual nontriptan therapy. Usual nontriptan medications included NSAIDs (57\%), simple analgesics $(27 \%)$, or ergot derivatives (16\%). $78.8 \%$ of patients preferred rizatriptan $(\mathrm{p}<0.001)$. The most common reasons cited for preference were faster relief of headache and faster return to normal function. A similar study by Bell and colleagues ${ }^{14}$ compared rizatriptan $10 \mathrm{mg}$ tabs with usual-care medications. These medications included sumatriptan $(48.9 \%)$, zolmitriptan $(15.8 \%)$, eletriptan $(12.9 \%)$, almotriptan (12.0\%), NSAIDs (5.4\%), butalbital-containing combinations $(4.3 \%)$ and isometheptene $(3.4 \%)$. In terms of preference, $19.6 \%$ did not express a preference. Of the 1,147 patients who did express a preference, $58 \%$ preferred rizatriptan $(\mathrm{p}<0.001)$.

A different type of study by Láinez and colleagues ${ }^{15}$ looked at productivity and quality of life, as well as preference for rizatriptan over usual medications. This was a prospective, open-label study at 27 work sites in Spain. Patients completed study questionnaires to assess quality of life: ML-96, and the
Short Form Health Survey (SF-36) at baseline and then three months later. The ML-96 questionnaire has two parts. The first part evaluates the use of medical resources, and the second part assesses the effect of migraine on work loss and productivity. The SF-36 questionnaire is a validated tool designed to measure general health-related quality of life. Questions look at three aspects of health: functional status, well-being, and perception of health. 259 patients completed the study. Only $7 \%$ had taken triptans in the past. Patients were instructed to treat moderate to severe migraines with rizatriptan $10 \mathrm{mg}$ tabs, for the three-month duration of the study. After three months of rizatriptan therapy, the use of medical services was much lower, absenteeism from work was lower, and quality of life had improved ( $\mathrm{p}<0.001) .89 \%$ preferred rizatriptan over their usual medications. Again, the most common reason for preference was rapid speed of headache relief.

\section{Patient satisfaction}

Patient satisfaction with therapy at two hours post-treatment was evaluated as a secondary outcome in six double-blind, randomized trials of rizatriptan versus placebo. ${ }^{16-21}$ Patients rated their satisfaction with the study treatment on a sevenpoint scale, with 1 = completely satisfied, couldn't be better; 2 = very satisfied; $3=$ somewhat satisfied; $4=$ neither satisfied nor dissatisfied; $5=$ somewhat dissatisfied; $6=$ very dissatisfied; 7 = completely dissatisfied, couldn't be worse. Combination of data from the six trials using meta-analysis was performed (see Figure 2). The odds of being completely, very or somewhat satisfied using rizatriptan versus placebo was 4.62 (95\% CI: 3.36, 6.36; p $<0.00001)$.

Patient satisfaction with rizatriptan versus another triptan (sumatriptan, naratriptan, zolmitriptan) at two hours was

\begin{tabular}{|c|c|c|c|c|c|c|c|c|}
\hline \multirow[b]{2}{*}{ Study or subgroup } & \multicolumn{2}{|c|}{ Rizatriptan } & \multicolumn{2}{|c|}{ Placebo } & \multirow[b]{2}{*}{ Weight } & \multirow{2}{*}{$\begin{array}{c}\text { Odds ratio } \\
\text { M-H, Random, } 95 \% \mathrm{Cl}\end{array}$} & \multirow{2}{*}{\multicolumn{2}{|c|}{$\begin{array}{c}\text { Odds ratio } \\
\text { M-H, Random, } 95 \% \mathrm{Cl}\end{array}$}} \\
\hline & Events & Total & Events & Total & & & & \\
\hline Bomhof, $1999^{17}$ & 108 & 192 & 16 & 101 & $13.3 \%$ & $6.83[3.73,12.51]$ & & \\
\hline Freitag, $2008^{18}$ & 117 & 185 & 40 & 92 & $15.5 \%$ & $2.24[1.34,3.72]$ & & $\longrightarrow$ \\
\hline Goldstein, $1998^{16}$ & 695 & 1112 & 119 & 428 & $22.3 \%$ & $4.33[3.39,5.52]$ & & \\
\hline Kramer, $1998^{19}$ & 224 & 324 & 17 & 83 & $13.8 \%$ & $8.70[4.86,15.58]$ & & 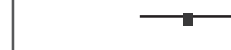 \\
\hline Pascual, $2000^{20}$ & 183 & 292 & 34 & 146 & $16.9 \%$ & $5.53[3.52,8.68]$ & & $\pi$ \\
\hline Tfelt Hansen, $1998^{21}$ & 224 & 380 & 44 & 156 & $18.1 \%$ & $3.66[2.44,5.48]$ & & \\
\hline Total $(95 \% \mathrm{Cl})$ & & 2485 & & 1006 & $100.0 \%$ & $4.62[3.36,6.36]$ & & \\
\hline Total events & 1551 & & 270 & & & & & \\
\hline $\begin{array}{l}\text { Heterogeneity: } \text { Tau }^{2}= \\
\text { Test for overall effect: }\end{array}$ & $\begin{array}{l}10 ; \mathrm{Chi}^{2} \\
=9.40(\end{array}$ & $\begin{array}{l}=15.87 \\
P<0.0 C\end{array}$ & $\begin{array}{l}\mathrm{df}=5(\mathrm{f} \\
001)\end{array}$ & $P=0.0$ & $07) ; 1^{2}=69$ & & $\begin{array}{ccc}0.1 & 0.2 & 0.5 \\
\text { Favors placebo }\end{array}$ & $\begin{array}{llll}1 & 2 & 5 & 10 \\
\text { Favors rizatriptan }\end{array}$ \\
\hline
\end{tabular}

Figure 2 Patient satisfaction; rizatriptan versus placebo. 
evaluated as a secondary outcome in four double-blind, randomized trials. ${ }^{16,17,20,21}$ Meta-analysis of the data from the four trials was performed (see Figure 3). Patients taking rizatriptan were 1.32 times more likely to be completely, very or somewhat satisfied compared to those taking another $\operatorname{triptan}(95 \% \mathrm{CI}: 1.09,1.60 ; \mathrm{p}=0.005)$.

One trial compared patient satisfaction with rizatriptan $10 \mathrm{mg}$ versus ergotamine/caffeine in a double-blind crossover trial of 439 patients treating a single migraine attack with each therapy. ${ }^{12}$ Two hours after dosing, $69.8 \%$ of patients were completely, very or somewhat satisfied with rizatriptan, compared to $38.6 \%$ with ergotamine/caffeine $(p<0.001)$.

\section{Health-related quality of life}

Five clinical trials of rizatriptan have assessed quality of life as a secondary outcome; four double-blind, randomized trials of rizatriptan versus placebo (and zolmitriptan in one trial), and one open-label extension trial of rizatriptan versus standard care. All studies used the 24-hour Migraine Quality of Life Questionnaire; the open-label trial also measured general health-related quality of life using the SF-36. The 24-hour Migraine Quality of Life Questionnaire is a validated instrument, consisting of 15 questions divided into five domains: work functioning, social functioning, energy/vitality, migraine symptoms, and feelings/concerns. As the description of the study results was quite limited in three of the double-blind trials, and due to clinical heterogeneity of the remaining trials, the results were not combined using meta-analysis (see Table 3 for summary of study data).

Santanello and colleagues ${ }^{22}$ reported the effects of rizatriptan on migraine-specific quality of life in 247 patients participating in a substudy of a large randomized, doubleblind, placebo-controlled trial of rizatriptan $2.5 \mathrm{mg}, 5 \mathrm{mg}$, $10 \mathrm{mg}$, or placebo. Patients treated one moderate or severe migraine attack with study medication and completed the 24-hour Migraine Quality of Life Questionnaire 24 hours after ingesting the test medication. The study found a significant linear dose response for each of the domain scores in the 24-hour Migraine Quality of Life Questionnaire. Statistically significant mean improvements were observed for patients treated with rizatriptan $10 \mathrm{mg}$ compared with those treated with placebo in the social functioning, migraine symptoms, and feelings/concerns domains. Patients receiving rizatriptan $10 \mathrm{mg}$ experienced significantly better overall migrainespecific quality of life compared to those on placebo.

Migraine-specific quality of life in patients using rizatriptan 5 or $10 \mathrm{mg}$ versus placebo was also briefly described in Teall's study $^{23}$ of 1473 patients, and Ahrens' study ${ }^{24}$ of 634 patients. Teall reported that both doses of rizatriptan resulted in a significant improvement in quality of life scores in all domains over placebo, while Ahrens' reported that the rizatriptan $10 \mathrm{mg}$ wafer was statistically superior to the $5 \mathrm{mg}$ dose in improving quality of life at 24 hours post-dose. Pascual's study ${ }^{20}$ of rizatriptan $10 \mathrm{mg}$ versus zolmitriptan $2.5 \mathrm{mg}$ and placebo in 776 patients reported that both rizatriptan and zolmitriptan were superior to placebo on all five quality of life domains and there were no differences between the active treatments.

Gerth and colleagues ${ }^{25}$ reported the effect of rizatriptan on migraine-specific quality of life at 24 hours and general health-related quality of life in a 12-month open-label extension trial of rizatriptan $10 \mathrm{mg}$ versus standard care (which was sumatriptan for the majority of patients). 265 patients completed the 24-hour Migraine Quality of Life Questionnaire over the first month of the trial, and the SF-36 at baseline and at 2, 6, and 12 months. Patients randomized to rizatriptan $10 \mathrm{mg}$ had significantly better scores in all five domains of the 24-hour Migraine Quality of Life Questionnaire instrument. The magnitude of increase ranged from $11 \%$ in the work functioning domain to $26 \%$ in the feelings/concerns domain. With respect to general health-related quality of life,

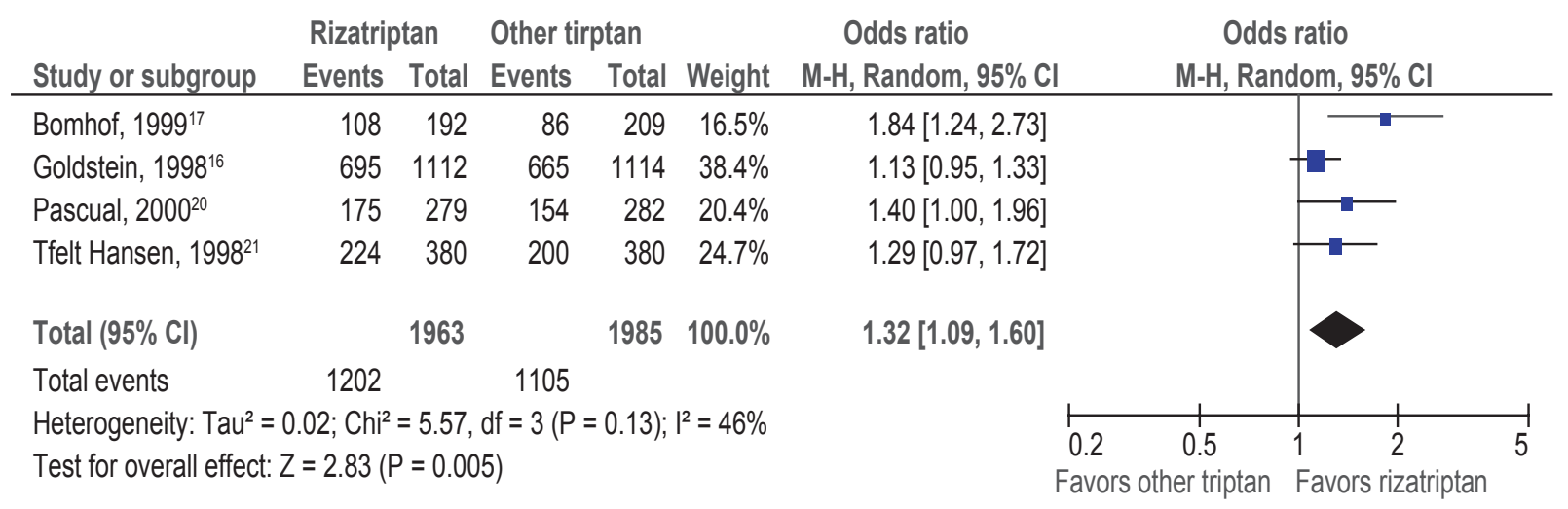

Figure 3 Patient satisfaction; rizatriptan versus other triptans. 
Table 3 Summary of studies on rizatriptan and quality of life

\begin{tabular}{|c|c|c|c|c|}
\hline Study & Comparison & Sample size & Outcome studied & Results \\
\hline Santanello, $1997^{22}$ & $\begin{array}{l}\text { Placebo, rizatriptan } \\
2.5 \mathrm{mg}, 5 \mathrm{mg} \text { or } 10 \mathrm{mg}\end{array}$ & $n=247$ & 24 h MQoLQ & $\begin{array}{l}\text { Improvement in three of five domains } \\
\text { of } 24 \mathrm{~h} \text { MQoLQ in rizatriptan } 10 \mathrm{mg} \\
\text { group compared to placebo: social } \\
\text { functioning, migraine symptoms, and } \\
\text { feelings/concerns }\end{array}$ \\
\hline Teall, $1998^{23}$ & $\begin{array}{l}\text { Placebo, rizatriptan } 5 \mathrm{mg} \\
\text { or } 10 \mathrm{mg}\end{array}$ & $\mathrm{n}=1473$ & 24 h MQoLQ & $\begin{array}{l}\text { Improvement in all five domains of } \\
24 \mathrm{~h} \text { MQoLQ in rizatriptan } 5 \mathrm{mg} \text { and } \\
10 \mathrm{mg} \text { group compared to placebo }\end{array}$ \\
\hline Ahrens, 199924 & $\begin{array}{l}\text { Placebo, rizatriptan } 5 \mathrm{mg} \\
\text { or } 10 \mathrm{mg}\end{array}$ & $\mathrm{n}=634$ & 24 h MQoLQ & $\begin{array}{l}\text { Rizatriptan } 10 \mathrm{mg} \text { superior to } 5 \mathrm{mg} \\
\text { dose in improving quality of life }\end{array}$ \\
\hline Pascual, $2000^{20}$ & $\begin{array}{l}\text { Placebo, rizatriptan } 10 \mathrm{mg} \text {, } \\
\text { or zolmitriptan } 2.5 \mathrm{mg}\end{array}$ & $n=776$ & 24 h MQoLQ & $\begin{array}{l}\text { Rizatriptan } 10 \mathrm{mg} \text { and zolmitriptan } \\
2.5 \mathrm{mg} \text { superior to placebo in all five } \\
\text { quality of life domains }\end{array}$ \\
\hline Gerth, 200I 25 & $\begin{array}{l}\text { Rizatriptan } 10 \mathrm{mg} \text { or } \\
\text { standard care }\end{array}$ & $n=265$ & 24 h MQoLQ SF-36 & $\begin{array}{l}\text { Rizatriptan } 10 \mathrm{mg} \text { superior to standard } \\
\text { care in all five domains of } 24 \mathrm{~h} \text { MQoLQ; } \\
\text { significant improvement from baseline } \\
\text { in mental health domain of SF- } 36\end{array}$ \\
\hline
\end{tabular}

Abbreviations: 24 h MQoLQ, 24-hour Migraine Quality of Life Questionnaire; SF-36, Short Form Health Survey.

a significant improvement from baseline was only observed in the mental health domain of the SF-36.

\section{Discussion}

Rizatriptan is an effective therapy for acute migraine headaches, as demonstrated by multiple randomized doubleblind placebo-controlled studies. In reviewing the literature on consistency of effect, preference, satisfaction, and quality of life for rizatriptan, we can make the following conclusions.

Rizatriptan in most studies shows quite a good consistency of effect, in the range of $70 \%$ to $80 \%$ of attacks. There does not seem to be any tolerance or loss of efficacy with repeated use. Studies also indicate that rizatriptan is generally preferred over other triptans and nontriptan medications for acute migraine headaches. The majority of the studies on patient preference however were open-label and therefore unblinded. Although this is not uncommon in preference studies, biases may have entered these studies, from both the investigators and the patients. Most of the studies were financially sponsored by Merck Frosst, the maker of rizatriptan. ${ }^{3,4,6-8,10,12-15}$ This bias likely resulted in the preference comparison of rizatriptan to the $50 \mathrm{mg}$ dose of sumatriptan, rather than the $100 \mathrm{mg}$ dose, which may be more effective than the lower dose of sumatriptan in some patients. ${ }^{26}$ Furthermore, most studies compared only two attacks - one attack for each medication - which may not be enough time to determine whether a medication is effective and well tolerated.

The most important reason found for the preference of rizatriptan over other treatments was speed of headache relief.
In clinical practice, it must be appreciated that each patient is unique, and that some patients respond to one triptan better than another triptan for reasons which are not understood. Given this fact, in many headache clinics, patients are given samples of two different triptans and asked to report back on which medication they felt was most effective for their migraine attack.

Patient satisfaction with rizatriptan is consistently higher than placebo, with convincing evidence of a greater than four-fold odds of satisfaction with rizatriptan over placebo. Greater patient satisfaction with rizatriptan than other triptans is less convincing. Only one of the four studies comparing patient satisfaction with rizatriptan to other triptans had a confidence interval that did not cross 1.0 (suggesting no difference between treatments), Bomhoff's study of rizatriptan versus naratriptan $2.5 \mathrm{mg}$. It is not surprising that rizatriptan was rated more satisfactory than its competitor in this study. Naratriptan has the slowest onset of action of all the triptans, with significant pain response rates at four hours rather than two hours. ${ }^{27}$ As speed of relief is highly valued by patients, it is more likely they will report greater satisfaction with a medication which has quicker onset to relief. Based on the summary of these results, there is no convincing evidence that patient satisfaction with rizatriptan exceeds that of other triptans, with the exception of naratriptan.

Migraine-specific quality of life at 24 hours appears reliably improved in patients using rizatriptan in comparison to placebo. Overall quality of life appears unaffected, with the exception of the mental health domain. Given that the SF-36 
is a generic health-related quality of life measure, it likely does not have the sensitivity to reliably detect small changes in overall function in patients with migraine. A quality of life measure which is more specific to patients with chronic pain would probably yield more impressive changes over time from effective migraine therapy. Certainly in clinical practice, when patients have effective, reliable acute therapy, they feel freer to perform activities, live more spontaneously and less in fear of their migraine attacks.

In conclusion, there is good evidence to support that rizatriptan is an effective, consistently successful treatment for migraine headache that patients prefer over other therapies, and which patients feel satisfied with. Rizatriptan improves migraine-specific quality of life at 24 hours.

\section{Disclosures}

The authors report no conflicts of interest in this work.

\section{References}

1. Ferrari MD, Roon KI, Lipton RB, Goadsby PJ. Oral triptans in acute migraine treatment: a meta-analysis of 53 trials. Cephalalgia. 2002; 22:633-658.

2. Dowson JA, Tepper SJ, Dahlof C. Patients' preference for triptans and other medications as a tool for assessing the efficacy of acute treatments for migraine. J Headache Pain. 2005;6:112-120.

3. Dahlof CGH, Lipton RB, McCarroll KA, Kramer MS, Lines CR, Ferrari MD. Within-patient consistency of response of rizatriptan for treating migraine. Neurology. 2000;55:1511-1516.

4. Block GA, Goldstein J, Polis A, Reines SA, Smith ME; the Rizatriptan Multicenter Study Groups. Efficacy and safety of rizatriptan versus standard care during long-term treatment for migraine. Headache. 1998;38:764-771.

5. Göbel H, Heinze A, Heinze-Kuhn K, Lindner V. Efficacy and tolerability of rizatriptan $10 \mathrm{mg}$ in migraine: experience with 70527 patient episodes. Headache. 2001;41:264-270.

6. Láinez MJ, Evers S, Kinge E, et al. Preference for rizatriptan 10-mg wafer vs eletriptan 40-mg tablet for acute treatment of migraine. Cephalalgia. 2006;26:246-256.

7. Loder E, Brandes JL, Silberstein S, et al; Rizatriptan Protocol 060 Study Group. Preference comparison of rizatriptan ODT 10-mg and sumatriptan 50-mg tablet in migraine. Headache. 2001;41:745-753.

8. Pascual J, Bussone G, Hernandez JF, Allen C, Vrijens F, Patel K; Rizatriptan-Sumatriptan Preference Study Group. Comparison of preference for rizatriptan 10-mg wafer versus sumatriptan 50-mg tablet in migraine. Eur Neurol. 2001;45:275-283.

9. Díez FI, Straube A, Zanchin G. Patient preference in migraine therapy. A randomized, open-label, crossover clinical trial of acute treatment of migraine with oral almotriptan and rizatriptan. J Neurol. 2007; 254:242-249.

Patient Preference and Adherence

\section{Publish your work in this journal}

Patient Preference and Adherence is an international, peer-reviewed, open access journal that focusing on the growing importance of patient preference and adherence throughout the therapeutic continuum. Patient satisfaction, acceptability, quality of life, compliance, persistence and their role in developing new therapeutic modalities and compounds to
10. Ng-Mak DS, Hu XH, Chen Y, Ma L, Solomon G. Times to pain relief and pain freedom with rizatriptan $10 \mathrm{mg}$ and other oral triptans. Int $J$ Clin Pract, 2007;61:1091-1111.

11. Adelman JU, Mannix LK, Von Seggern RL. Rizatriptan tablet versus wafer: patient preference. Headache. 2000;40:371-372.

12. Christie S, Göbel H, Mateos V, Allen C, Vrijens F, Shivaprakash M; Rizatriptan-Ergotamine/Caffeine Preference Study Group. Crossover comparison of efficacy and preference for rizatriptan $10 \mathrm{mg}$ versus ergotamine/caffeine in migraine. Eur Neurol. 2003;49:20-29.

13. Pascual J, García-Moncó C, Roig C, Yusta Izquierdo A, López-Gil A; eMAX Study Group. Rizatriptan 10-mg wafer versus usual nontriptan therapy for migraine: Analysis of Return to Function and Patient Preference. Headache. 2005;45:1140-1150.

14. Bell CF, Foley KA, Barlas S, Solomon G, Hu XH. Time to pain freedom and onset of pain relief with rizatriptan $10 \mathrm{mg}$ and prescription usualcare oral medications in the acute treatment of migraine headaches: A multicenter, prospective, open-label, two-attack, crossover study. Clin Ther. 2006;28:872-880.

15. Láinez MJA, Lopez A, Pacual AM. Effects on productivity and quality of life of rizatriptan for acute migraine: a workplace study. Headache. 2005;45:883-890.

16. Goldstein J, Ryan R, Jiang K, et al. Crossover comparison of rizatriptan $5 \mathrm{mg}$ and $10 \mathrm{mg}$ versus sumatriptan $25 \mathrm{mg}$ and $50 \mathrm{mg}$ in migraine. Headache. 1998;38:737-747.

17. Bomhof M, Paz J, Legg N, Allen C, Vandormael K, Patel K. Comparison of rizatriptan $10 \mathrm{mg}$ vs naratriptan $2.5 \mathrm{mg}$ in migraine. Eur Neurol. 1999;42:173-179.

18. Freitag F, Taylor F, Hamid M, et al. Elimination of migraine associated nausea in patients treated with rizatriptan orally disintegrating tablet: a randomized double blind placebo controlled study. Headache. 2008;48:368-377.

19. Kramer M, Matzura-Wolfe D, Polis A, et al. A placebo-controlled crossover study of rizatriptan in the treatment of multiple migraine attacks. Neurology. 1998;51:773-781.

20. Pascual J, Vega P, Diener H, Allen C, Vrijens F, Patel K. Comparison of rizatriptan $10 \mathrm{mg}$ vs zolmitriptan $2.5 \mathrm{mg}$ in the acute treatment of migraine. Cephalalgia. 2000;20:455-461.

21. Tfelt-Hansen P, Teall J, Rodriguez F, et al. Oral rizatriptan versus oral sumatriptan: a direct comparative study in the acute treatment of migraine. Headache. 1998;38:748-755.

22. Santanello N, Polis A, Hartmaier S, Kramer M, Block G, Silberstein S. Improvement in migraine specific quality of life in a clinical trial of rizatriptan. Cephalalgia. 1997;17:867-872.

23. Teall J, Tuchman M, Cutler N. Rizatriptan for the acute treatment of migraine and migraine recurrence. A placebo controlled, outpatient study. Headache. 1998;38:281-287.

24. Ahrens S, Farmer M, Williams D, et al. Efficacy and safety of rizatriptan wafer for the acute treatment of migraine. Cephalalgia. 1999;19:525-530.

25. Gerth W, Ruggles K, Stark S, Davies G, Santanello N. Improvement in health related quality of life with rizatriptan $10 \mathrm{mg}$ compared with standard migraine therapy. Clin Drug Invest. 2001;21:853-860.

26. Cutler N, Mushet G, Davis R, Clements B, Whitcher L. Oral sumatriptan for the acute treatment of migraine: evaluation of three dosage strengths. Neurology. 1995;45(8 Suppl 7):S5-S9.

27. Mathew N, Asqharnejad M, Peykamian M, Laurenza A. Naratriptan is effective and well tolerated in the acute treatment of migraine. Neurology. 1997;49:1485-1490.

\section{Dovepress}

optimize clinical outcomes for existing disease states are major areas of interest. This journal has been accepted for indexing on PubMed Central. The manuscript management system is completely online and includes a very quick and fair peer-review system. Visit http://www.dovepress.com/ testimonials.php to read real quotes from published authors. 